\title{
FORMULATION AND EVALUATION OF CREAMS CONTAINING CELECOXIB INCLUSIONS FOR TREATING PSORIATIC ARTHRITIS
}

\author{
ROOPA RANI N, SUDHARSHAN B, SHIVA PULLA REDDY G, PADMINI IRIVENTI* \\ Department of Pharmaceutics, Dr. K.V. Subba Reddy Institute of Pharmacy, Kurnool, Andhra Pradesh, India. \\ Email: paddhu.iriventi@gmail.com
}

Received: 05 March 2020, Revised and Accepted: 07 April 2020

\begin{abstract}
Objective: The main objective of the present work was to prepare and evaluate creams of celecoxib inclusions which are nonsteroidal antiinflammatory drug to treat psoriatic arthritis.

Methods: Celecoxib inclusions were prepared using $\beta$-cyclodextrin to increase the solubility. These inclusions were incorporated in creams. Cocoa butter, triethanolamine, stearic acid, methylparaben, gum acacia, and coconut oil were used in cream preparation. Fourier transform infrared and differential scanning calorimetry studies were carried out for pure celecoxib and inclusions. Viscosity, pH, homogeneity, and type of emulsion under dye test were evaluation parameters done for creams.
\end{abstract}

Results: All the results obtained were within the limits and confirmed increased solubility of celecoxib inclusions.

Conclusion: From the results obtained, increase in solubility of celecoxib drug was confirmed by forming inclusions using $\beta$-CD as polymer.

Keywords: $\beta$-cyclodextrin, Psoriatic Arthritis, Creams, Celecoxib, Inclusions.

(C) 2020 The Authors. Published by Innovare Academic Sciences Pvt Ltd. This is an open access article under the CC BY license (http://creativecommons. org/licenses/by/4. 0/) DOI: http://dx.doi.org/10.22159/ajpcr.2020.v13i4.37469

\section{INTRODUCTION}

Psoriatic arthritis (PsA) is a chronic, systemic, and inflammatory disease that affects peripheral joints, connective tissues, and axial skeleton and is associated with psoriasis of skin and nails [1,2]. PsA is a seronegative inflammatory arthropathy that occurs in $5-7 \%$ of people with psoriasis $[3,4]$. It is thought that environmental triggers which are infectious in nature, triggers the disease in genetically susceptible individuals [5]. Currently available therapies for PsA are surgery, light therapy, narrowband ultraviolet (UV) B phototherapy, excimer laser, and psoralen and ultraviolet A (PUVA) [6]. Available drugs are corticosteroids, tacrolimus, tumor necrosis factor inhibitors, methotrexate, and sulfasalazine [7]. The disadvantages of these drugs are the radiation can dry out the skin and cause itching and redness, burning, blistering of the skin, etc. [8]. Celecoxib is a cyclooxygenase-2 (COX-2)-specific inhibiting agent that inhibits the conversion of arachidonic acid to the prostaglandins that mediate pain and inflammation [9]. In theory, a drug such as celecoxib that selectively inhibits COX-2 might block inflammation, pain, and fever [10]. Creams refer to disperse systems, in which one insoluble phase is dispersed as droplets in a second liquid phase. Creams are often preferred over other topical preparations because they are less irritating and easy to apply [11]. $\beta$-cyclodextrins are widely used in the pharmaceutical field for their ability of improving the solubility and the stability of drugs by complex formation at the solid state [12]. The use of cyclodextrins and their derivatives can encapsulate the bioactive compounds and protect the compounds from environmental conditions and improves the aqueous solubility and increases their capacity to function [13]. In the present study, an attempt has been made to develop inclusions (complexes) of celecoxib using $\beta$-CD. These inclusions are prepared to increase the solubility of the drug which is poorly water soluble. Prepared inclusions are incorporated into creams to obtain formulations for which further evaluation studies have been conducted.

\section{METHODS}

Celecoxib is a gift sample obtained from Wexford Laboratories Pvt., Ltd., Bengaluru. $\beta$-cyclodextrin was obtained from HiMedia, India. Cocoa butter was procured Rolex Chem Industries, India. Stearic acid and methylparaben were obtained from Qualikems Fine Chemicals Pvt. Ltd., Vadodara. Gum acacia was obtained from SD Fine-Chem Limited, Mumbai, triethanolamine from Pallav Chemicals and Solvents Pvt., Ltd., Boisar, India, and coconut oil from Herbs Nutri Products Pvt., Ltd., Mumbai.

\section{Methodology}

Solubility studies of celecoxib in water and in $\mathrm{pH} 7.4$ buffer

Drug solubility was determined by adding excess amount of pure celecoxib in water and $\mathrm{pH} 7.4$ phosphate buffer at $37 \pm 0.5^{\circ} \mathrm{C}$ in vials, respectively. These vials were kept in orbital shaker for $24 \mathrm{~h}$ at $100 \mathrm{rpm}$. Final solution was filtered through membrane filter $0.45 \mu \mathrm{m}$. The concentration of the samples was measured using UV-visible spectrophotometer (UV 1800, Shimadzu, Japan). Each sample was analyzed in triplicate.

\section{Analytical method for celecoxib}

Calibration curve in $\mathrm{pH} 7.4$ phosphate buffer

From the standard solution, a stock solution was prepared to give a concentration of $100 \mu \mathrm{g} / \mathrm{ml}$ in 7.4 buffer. Aliquots of $0.5,1.0,1.5,2.0$, and $2.5 \mathrm{ml}$ from the stock solution were pipetted out into $10 \mathrm{ml}$ volumetric flasks. The volume was made up to the mark with 7.4 buffer. These dilutions gave $5,10,15,20$, and $25 \mu \mathrm{g} / \mathrm{ml}$ concentration of celecoxib, respectively. The absorbance of prepared solutions of celecoxib in 7.4 buffer was measured at $252 \mathrm{~nm}$ spectrophotometrically against 7.4 buffer blank. Standard plot data of celecoxib in 7.4 pH buffer are reported in Fig. 1.

Fourier-transform infrared (FT-IR) spectroscopy analysis FT-IR analysis was conducted to verify the interaction between drug and polymer. The sample powder was dispersed in KBr powder and 
pellets were made by applying $4 \mathrm{~kg} / \mathrm{cm}^{2}$ pressure. FT-IR spectra were obtained by powder diffuse reflectance on a FT-IR spectrophotometer type 8400S Shimadzu. It was performed for pure celecoxib drug and F2 formulation

\section{Differential scanning calorimetry (DSC)}

DSC was performed on pure drug and its formulations using DSC-60 instrument. Calorimetric measurements were made with empty cell (high purity alpha alumina discs) as the reference. The dynamic scans were taken in nitrogen atmosphere at the heating rate of $10^{\circ} \mathrm{C} \mathrm{min}^{-1}$. The energy was measured as $\mathrm{J} / \mathrm{Kcal}$. It was performed for pure celecoxib drug and F2 formulation.

\section{Preparation of celecoxib cream}

Oil-in-water $(\mathrm{O} / \mathrm{W})$ emulsion-based cream (semisolid formulation) was formulated. The emulsifier (stearic acid) and other oil-soluble components (cocoa butter, acetyl alcohol, and coconut oil) were dissolved in the oil phase (Part A) and heated to $75^{\circ} \mathrm{C}$. The preservatives and other water-soluble components (methylparaben, triethanolamine, propylene glycol, and drug celecoxib inclusions) were dissolved in the aqueous phase (Part B) and heated to $75^{\circ} \mathrm{C}$. After heating, the aqueous phase was added in portions to the oil phase with continuous stirring and perfume was added [14]. The formulations of different creams prepared are given in Table 1.

\section{Evaluation of creams}

Type of emulsion under dye test

The scarlet red dye is mixed with the cream. A drop of the cream was placed on a microscopic slide and then it was covered with a cover slip and examined under a microscope. If the disperse globules appear red and the ground is colorless, the cream is 0/W type. The reverse condition occurs in W/O type cream, i.e., the disperse globules appear colorless in the red ground [15].

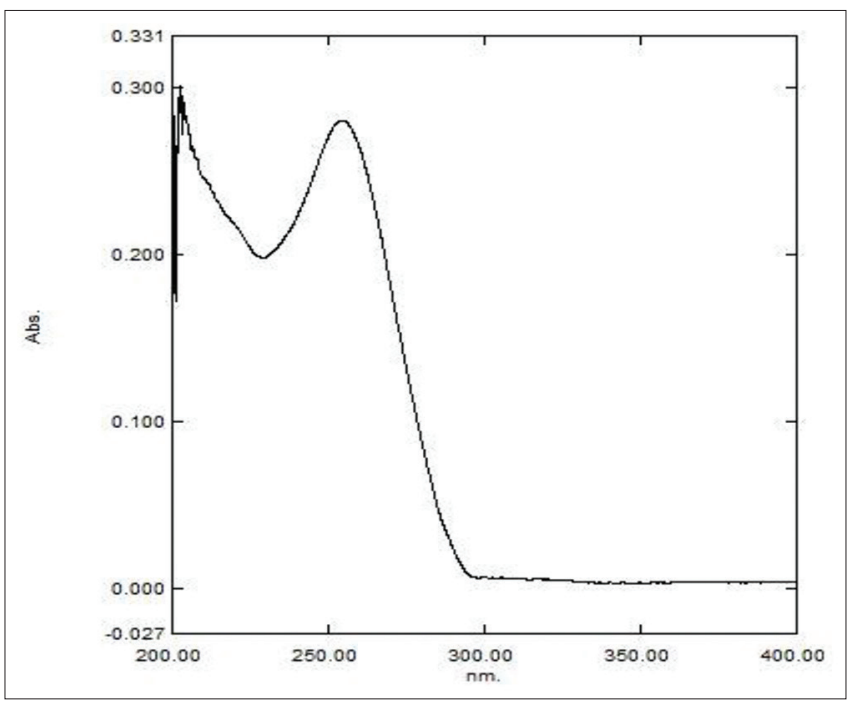

Fig. 1: Ultraviolet spectra of celecoxib in pH 7.4 phosphate buffer

Table 1: Formulation chart of creams (F1-F3)

\begin{tabular}{lllll}
\hline S. No. & Ingredients & F1 & F2 & F3 \\
\hline 1. & Celecoxib inclusions (mg) & 50 & 50 & 50 \\
2. & Cocoa butter (g) & 1 & 2 & 3 \\
3. & Stearic acid (g) & 1 & 2 & 3 \\
4. & Gum Acacia (\%) & 0.5 & 1 & 1.5 \\
5. & Coconut oil (ml) & 2 & 2 & 2 \\
6. & Methylparaben (\%) & 1 & 1 & 1 \\
7. & TEA (ml) & 0.5 & 0.5 & 0.5 \\
\hline
\end{tabular}

Appearance

The appearance of the cream was judged by its color, opalescence, and roughness and graded [15].

\section{Homogeneity}

The formulations were tested for the homogeneity by visual appearance and by touch [15]

$p H$

The $\mathrm{pH}$ meter was calibrated using standard buffer solution. About $0.5 \mathrm{~g}$ of the cream was weighed and dissolved in $50.0 \mathrm{ml}$ of distilled water and its $\mathrm{pH}$ was measured [15].

Viscosity

Viscosity of the formulation was determined by Brookfield Viscometer at $100 \mathrm{rpm}$, using spindle no. 7 [15].

\section{In vitro drug diffusion studies}

The F2 cream was permeated through a dialysis bag. A $0.5 \mathrm{~g}$ of cream was taken in the bag and is placed in a beaker containing phosphate buffer of $\mathrm{pH} 7.4$ and constantly stirred with a small magnetic bead. During the experiment, temperature was maintained at $37 \pm 0.5^{\circ} \mathrm{C}$ to simulate the human skin condition. A $5 \mathrm{ml}$ of samples were withdrawn at $0.5,1,2,6$, and $12 \mathrm{~h}$ and replaced with fresh receptor solution. The samples withdrawn were analyzed spectrophotometrically at $235 \mathrm{~nm}$. The amount of drug released was calculated and the percentage drug released was plotted against time.

Similarly, it was done for pure drug.

Statistical analysis (Analysis of variance [ANOVA])

Both the study and control groups were compared. ANOVA is performed for cream F2 and pure drug to determine the differences among the products tested.

\section{RESULTS AND DISCUSSION}

Solubility studies of celecoxib in water and in pH 7.4 buffer

From the results obtained, it was confirmed that solubility of celecoxib is more in $\mathrm{pH} 7.4$ buffer. Hence, further studies were carried out using pH 7.4 buffer. The results are given in Table 2.

\section{Evaluation studies}

Type of emulsion

Prepared cream was found to be $0 / \mathrm{W}$ emulsion. It shows that the cream has good spreadability and penetration on applying on the skin. Furthermore, it can be washed of easily.

Appearance

Prepared creams were light cream in color, opaque.

Homogeneity

Prepared creams are homogenous. No aggregates are present in the formulation.

$p H$

$\mathrm{pH}$ of the prepared creams was in the range of 6-7. It shows that obtained $\mathrm{pH}$ is near to skin $\mathrm{pH}$ and it does not cause any skin irritation.

Table 2: Solubility studies for celecoxib

Concentration of celecoxib in Concentration of celecoxib in $\mathrm{pH}$

water $(\mu \mathrm{g} / \mathrm{ml}) \quad \mathbf{7 . 4}(\mu \mathrm{g} / \mathrm{ml})$

\begin{tabular}{ll}
\hline $6.87(0.01)$ & $13.55 \pm 0.0057$ \\
\hline${ }^{*} \mathrm{n}=3[16]$ &
\end{tabular}


Viscosity

It was carried out by Brookfield Viscometer. Obtained viscosity was in the range of 2020-2060. It shows that F3 has higher viscosity (2060) and F1 has lowest (2020).

All the obtained results are given in Table 3.

From the above results, it was found that F2 cream has high viscosity. Hence, it is considered for further studies such as FTIR and DSC. F2 cream formulation is shown in Fig. 2.

\section{FT-IR studies}

The characteristic peaks of pure celecoxib and F2 formulation are shown in Fig. 3 and 4. From the data, it was observed that characteristic peaks of drug appeared almost similar in F2 spectrum with disappearance of some peaks. Hence, it can be inferred that there is no chemical interaction between drug and polymer and it can be concluded that the characteristic bands of pure drug were not affected by $\beta$-cyclodextrin and method used for preparation.

DSC

Thermogram of pure drug has shown a sharp endothermic peak at $163.10^{\circ} \mathrm{C}$, which corresponds to its melting point and is represented in Fig. 5. Formulation $\mathrm{F} 2$ has shown endothermic peak at $160.10^{\circ} \mathrm{C}$ which corresponds to the melting point of the drug and it is represented in Fig. 6. The DSC thermograms revealed that there was significant difference between the drug and the excipients. From the thermograms, it was evident that melting point of celecoxib was changed when it was formulated as complex. This was due to thermal transition behavior. Decrease in the

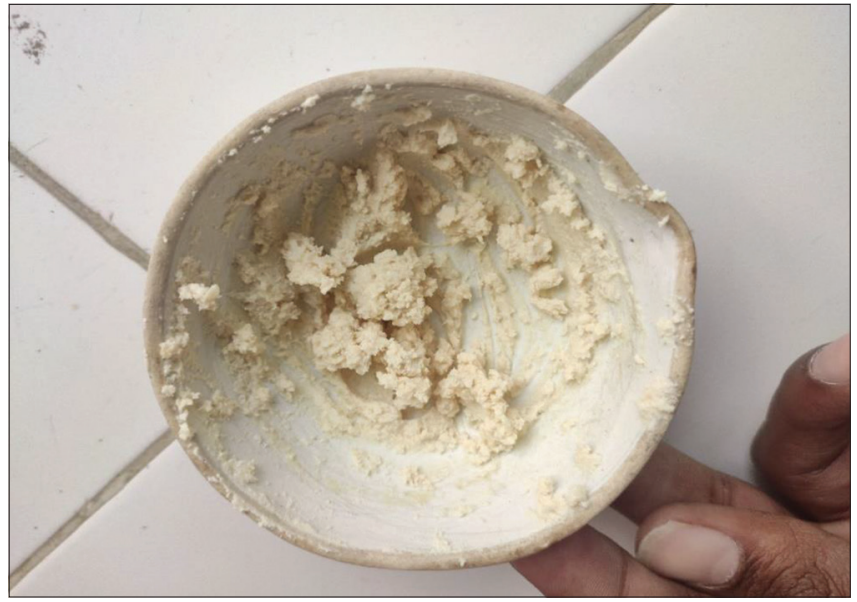

Fig. 2: Prepared cream formulation (F2) melting point of the drug was due to decrease in the crystallinity of the compound and also might be due displaced peak of drug.

\section{In vitro drug release studies}

In vitro drug release studies were carried out for both F2 formulation and pure drug. Pure drug has shown drug release for $8 \mathrm{~h}$ and after that no release was noticed, whereas F2 formulation has shown release till $24 \mathrm{~h}$ (Max 91.78\%). In case of F2 formulation, drug release occurred in prolonged manner. In the beginning, drug which is not encapsulated in the inclusions got released. This is the reason for increased \% drug release during initial hours. Then, after attaining saturation state, drug release from inclusions occurred. This was seen till $24 \mathrm{~h}$. However, in case of pure drug, no encapsulation of drug is seen hence release occurred till $8 \mathrm{~h}$ and also since celecoxib is poorly water soluble, drug release was also less. Drug release of both F2 formulation and pure drug is given in Table 4 and Fig. 7.

\section{Statistical analysis (ANOVA)}

ANOVA shows that in vitro results obtained by comparison between F5 and pure drug formulations have shown statistically significant differences $(p<0.05)$, as shown in Table 5 .

Table 3: Evaluation results of creams

\begin{tabular}{|c|c|c|c|c|}
\hline S. No. & $\begin{array}{l}\text { Evaluation } \\
\text { studies }\end{array}$ & F1 & F2 & F3 \\
\hline 1. & Appearance & Light cream & Light cream & Light cream \\
\hline 2. & Homogeneity & No aggregates & No aggregates & No aggregates \\
\hline 3. & Viscosity & 2020 & 2040 & 2060 \\
\hline 4. & $\mathrm{pH}$ & 6 & 7 & 7 \\
\hline
\end{tabular}

Table 4: In vitro \% drug release

\begin{tabular}{llll}
\hline S. No. & Time & F5 & Pure drug \\
\hline 1. & 0 & 0.00 & 0.00 \\
2. & 0.5 & 89.72 & 14.23 \\
3. & 1 & 76.98 & 28.45 \\
4. & 2 & 63.42 & 41.67 \\
5. & 4 & 59.43 & 54.82 \\
6. & 8 & 71.12 & 67.75 \\
7. & 12 & 82.43 & - \\
8. & 24 & 91.78 & - \\
\hline
\end{tabular}

Table 5: Statistical analysis (ANOVA)

\begin{tabular}{llll}
\hline $\begin{array}{l}\text { Newman-Keuls multiple } \\
\text { comparison test }\end{array}$ & $\begin{array}{l}\text { Mean } \\
\text { difference }\end{array}$ & q & Significant $(\mathbf{p}<\mathbf{0 . 0 5})$ \\
\hline F2 versus pure drug & -20.16 & 37.42 & Yes
\end{tabular}

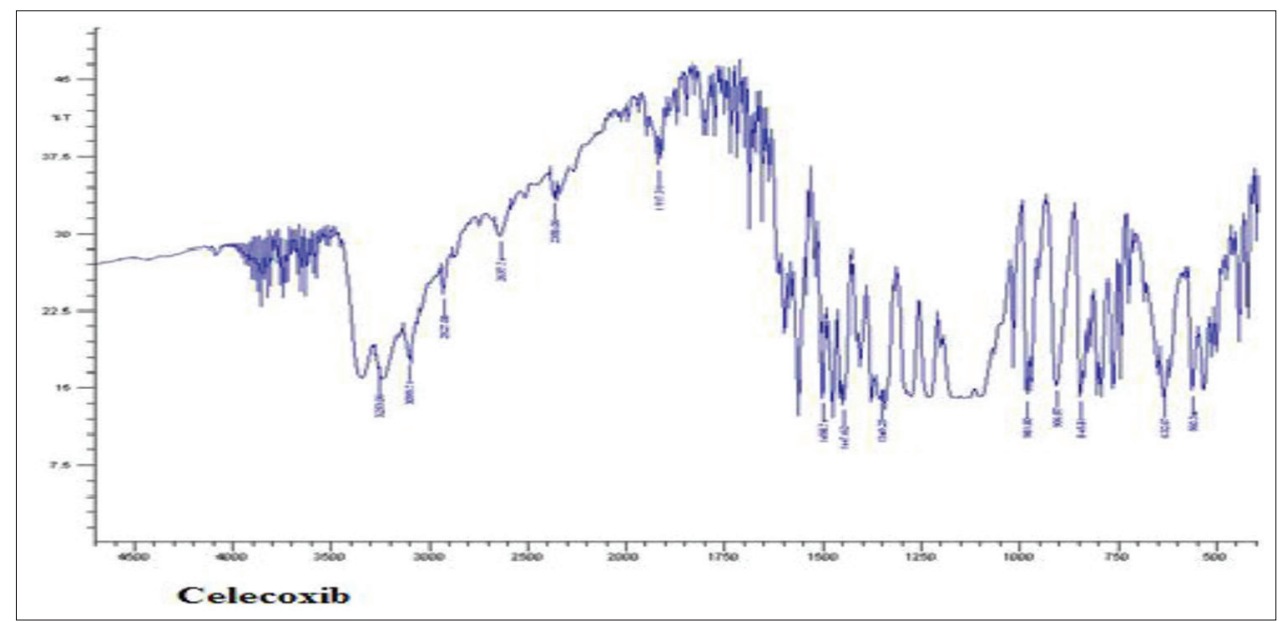

Fig. 3: Fourier transform infrared spectral data of pure celecoxib 


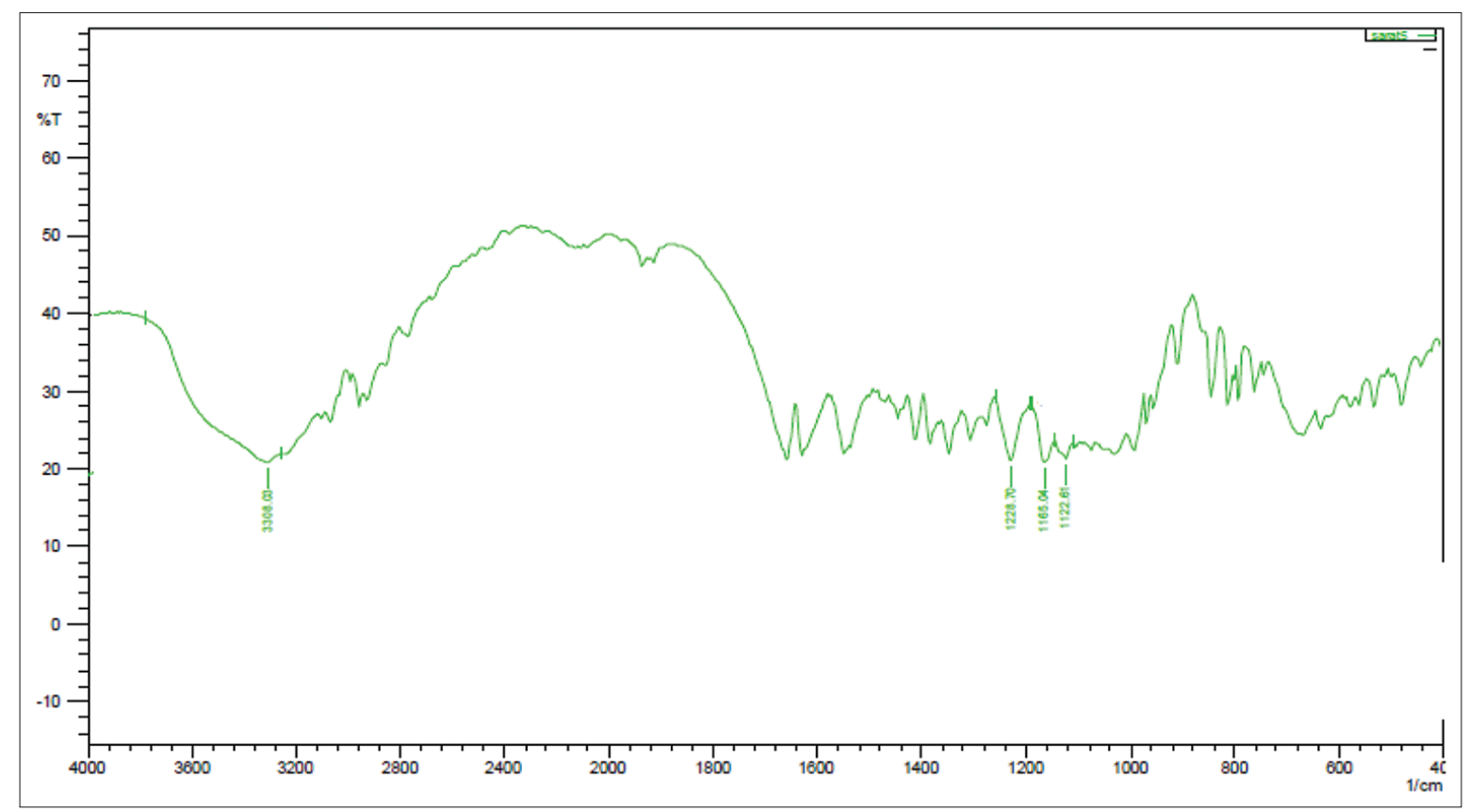

Fig. 4: Fourier transform infrared spectra of F2 formulation

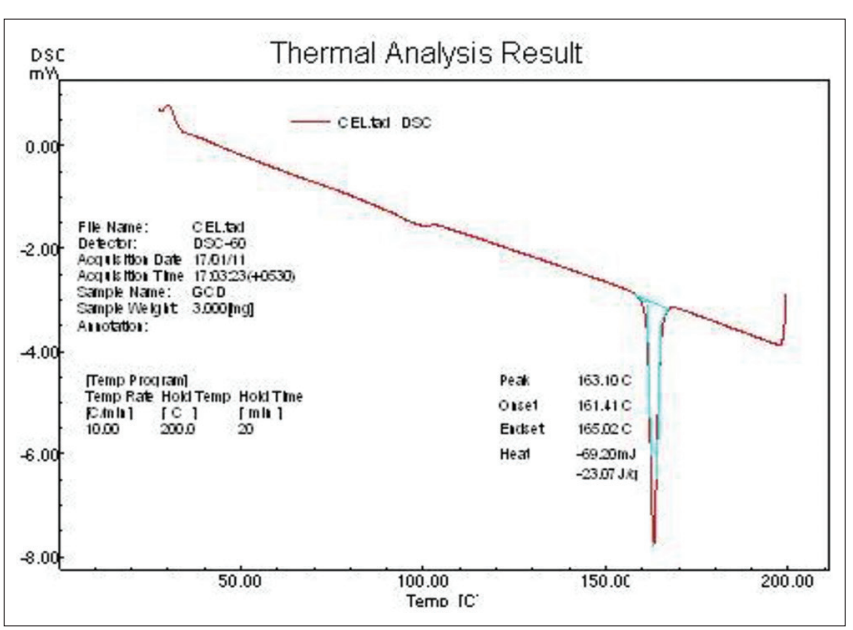

Fig. 5: Differential scanning calorimetry thermogram of pure celecoxib



Fig. 6: Differential scanning calorimetry thermogram of F2 formulation

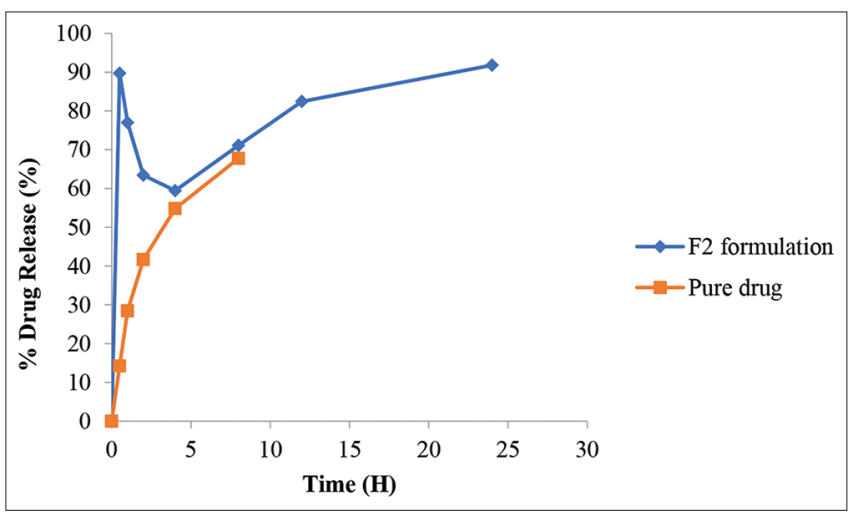

Fig. 7: Comparison of drug release between $F 2$ formulation and pure drug

\section{CONCLUSION}

Solubility of celecoxib drug was increased by forming inclusions using $\beta$-CD as polymer. This further leads to increased bioavailability. From FT-IR and DSC studies, compatibility between drug and polymer was confirmed. All the results obtained from evaluation parameters found to be within the limits and state that prepared creams were having good spreadability and no skin irritation on topical use. Prolonged release of celecoxib drug from $8 \mathrm{~h}$ to $24 \mathrm{~h}$ was achieved. This helps in decreasing the dose frequency of drug thus increases patient compliance.

\section{ACKNOWLEDGMENTS}

The author(s) express deep sense of gratitude toward Principal, Dr. K.V. Subba Reddy Institute of Pharmacy, Kurnool, for providing necessary facilities.

\section{AUTHORS' CONTRIBUTIONS}

All the authors contributed equally in preparation of manuscript.

\section{CONFLICTS OF INTEREST}

Authors have none to declare. 


\section{AUTHORS' FUNDING}

Authors did not receive any funding for the present work.

\section{REFERENCES}

1. Boehncke WH, Menter A. Burden of diseases, Psoriasis and psoriatic arthritis. Am J Clin Dermatol 2013;14:377-88.

2. Gladman DD, Antonic, Mease P, Clegg DO, Nash P. Psoriatic arthritis: Epidemiology, clinical features, course, outcome. Ann Rheum Dis 2005;64:ii14-7.

3. Carol MP. Pathophysiology: Concepts of Altered Health States. $7^{\text {th }}$ ed. Philadelphia, PA: Lippincott Williams and Wilkins; 2004. p. 1428-9.

4. Julsgaard M, Christensen LA, Gibson PR, Gearry RB, Fallingborg J, Hvas CL, et al. Concentrations of adalimumab and infliximab in mothers and newborns, and effects on infection. Gastroenterology 2016;151:110-9.

5. Damini N, Aniruddha M, Bina KM, Sugato B. Metabolic syndrome associated complications. Int J Pharm Pharm Sci 2015;7:22-5.

6. Camilla F. Genetic Studies of Psoriasis and Psoriatic Arthritis. Department of Medical and Clinical Genetics, Institute of Biomedicine. Gothenburg, Sweden: The Sahlgrenska Academy at Goteborg University Sweden; 2007.

7. DoQuyen H, Arthur K. Psoriatic arthritis: Current therapy and future approaches. Rheumatology 2015;54:20-8.
8. Eun JK, Arthur K. Psoriatic arthritis: Latest treatments and their place in therapy. Ther Adv Chronic Dis 2015;16:194-203.

9. Jayashree V, Prakash R. Protective effect of COX inhibitors on lipopolysaccharide induced sickness behaviour or neuroinflammation and oxidative stress on male wistar rats. Int $\mathrm{J}$ Pharm Pharm Sci 2015;7:240-5.

10. Baskar R, Joseph RS, Rajesh M, Subramanian I, Palanichamy S, Thangathirupathi A. Formulation and evaluation of celecoxib loaded nanosized emulsion as transdermal drug delivery vehicle. Int J Pharm Sci Res 2010;1:41-9.

11. Goyal A, Kumar S, Nagpal M, Singh I, Arora S. Potential of novel drug delivery systems for herbal drugs. Ind J Pharm Res Educ 2011;45:225-35.

12. Martini A, Torricelli C, Muggetti L, Ponti RD. Use of dehydrated beta-cyclodextrin as pharmaceutical excipient. Drug Dev Ind Pharm 2008;20:2381-93.

13. Benjamas C, Jaruporn R. Inclusion complex formation of cyclodextrin with its guest and their applications. Biol Eng Med 2016;2:1-6.

14. Asmita S, Prerana V, Sudha. Design, development and characterization of liposomal neem gel. Int J Pharm Sci Res 2014;5:140-8.

15. Mahendra SK, Nityanand PV. Wrightia tinctoria $\mathrm{R}$. Br. a review on its ethnobotany, pharmacognosy and pharmacological profile. J Coast Life Med 2014;2:826-40.

16. Shikha A, Nidhi S, Narendra. KJ, Agarwal GP. Solubility Enhancement of Poorly Water Soluble Celecoxib for Parenteral Formulations . Int. J. Pharm. Sci. Res 2012;3(7): 2325-36. 